\title{
Prospective issues for error detection
}

\author{
ADÉLAÏDE BLAVIER*, EMMANUELLE ROUY, \\ ANNE-SOPHIE NYSSEN and VÉRONIQUE DE KEYSER
}

\begin{abstract}
Université de Liège, Service de Psychologie du Travail, Boulevard du Rectorat 5 , 4000 Liège, Belgium
\end{abstract}

\begin{abstract}
From the literature on error detection, the authors select several concepts relating error detection mechanisms and prospective memory features. They emphasize the central role of intention in the classification of the errors into slips/lapses/mistakes, in the error handling process and in the usual distinction between action-based and outcome-based detection. Intention is again a core concept in their investigation of prospective memory theory, where they point out the contribution of intention retrievals, intention persistence and output monitoring in the individual's possibilities for detecting their errors. The involvement of the frontal lobes in prospective memory and in error detection is also analysed. From the chronology of a prospective memory task, the authors finally suggest a model for error detection also accounting for neural mechanisms highlighted by studies on error-related brain activity.
\end{abstract}

Keywords: Error detection; Prospective memory; Intention; Error-related brain activity

\section{Introduction}

Early studies on human error focused on the origins of errors and on the mechanisms involved in their production. This first phase research gave birth to various classifications according to the nature, the form and the consequences of human errors. A main effort was thus dedicated to the field of error prevention, leading sometimes to the elaboration of sophisticated aids. At that time it appeared necessary to account more effectively for contextual and organizational issues in the production of errors.

Recently, the focus moved progressively from error prevention towards error recovery and/or management. Safety systems are now a status quo and a new research trend considers that human error is inescapable (Amalberti 1996) and even that it is not desirable to eliminate it completely (Hasbroucq et al. 2000). The role of underlying factors in error production justifies both the continuation of studies on error prevention and the development of researches in order to master errors by reducing their consequences

*Corresponding author. Email: Adelaide.Blavier@ulg.ac.be 
(Reason 1990, Frese 1991, Amalberti 1996, Doireau et al. 1997, Nyssen 1997). Reducing the consequences of error not only means managing them, through tolerant systems, for example, but also recovering from them. And error recovery depends on error detection.

The mechanisms involved in the detection of errors or in their recovery remain little known. This paper intends to suggest new areas of investigation in order to identify what can help someone in the detection of their own errors. In the first part, a state of the art on error detection is presented. In the second part, there is an investigation into how the theoretical background of prospective memory (PM) and, more generally, the theory of intentions might provide new enlightenment. Finally, a model of reflection on the relationship between error detection and PM is proposed.

\section{Error and error detection}

\subsection{Definitions and classifications of error}

This investigation of error detection and error recovery was based on selected definitions and classifications of the various types of errors. An error can be defined as 'a non attainment of a goal' (Norman 1981, Reason 1990, Zapf et al. 1992, 1994). Another definition is 'a deviation from the norm' (Leplat 1985), 'when the individual had the prior intention and the possibility to reach this goal' (De Keyser and Nyssen 1993). The norm can be internal or external. Both these definitions emphasize the concepts of goal, norm and intention. One of the objectives was indeed to focus on their role in error detection and recovery processes. The second definition, in particular, is more precise and relates the error to the intention, a fundamental concept for Reason (1990) and Sellen (1990). Moreover, this definition points to internal and psychological aspects of the error (Reason 1990), being thus closer to the objective, namely focusing on the individual's role in error detection.

It is important to distinguish between the causes and the consequences of an error. Hollnagel (1998) calls 'phenotypes' the observable manifestations of the error and 'genotypes' the causes of the error. A phenotype can be explained by different genotypes and a genotype can be at the origin of various phenotypes.

Many works have dealt with the causes of error, i.e. with the various mechanisms involved in error production; these works have given rise to several taxonomies for error classifications. The first classification made by Reason (1990) distinguished mistakes, lapses and slips. However, at the present time, another classification devised by Reason, called generic error model system and established from Rasmussen's activity levels (1987), is most often used. This classification is one of the most famous in the literature because its decontextual aspect allows its use in all types of situations (Grant 1997, Kirwan 1998). Other classifications are presented and used, such as of Norman's (1981), which categorizes the slips according to three possible origins: the formation of the intention; the activation; the triggering. Another classification was established by Zapf et al. (1994) and classifies the error types in function of the level of action regulation (three levels). The different error classifications are summarized in table 1.

For what follows, the basic classification of Reason (1990) will be referred to, distinguishing between slips, lapses and mistakes. This error classification seems most useful for identifying the detection processes because it points out the individual's role in the occurrence of errors and, thus, their possibilities for detecting their own errors. This taxonomy allows the attribution of a possible origin to an error and to locate this error in one of the three main stages that range from the conception (planning) to the production 
Table 1. Different error taxonomies from literature

\begin{tabular}{|c|c|c|c|c|}
\hline $\begin{array}{l}\text { Cognitive } \\
\text { stages }\end{array}$ & $\begin{array}{l}(1990) \\
\text { Reason's first } \\
\text { classification }\end{array}$ & $\begin{array}{l}(1990) \\
\text { Reason's second } \\
\text { classification (GEMS) }\end{array}$ & $\begin{array}{l}(1981) \\
\text { Norman's } \\
\text { classification }\end{array}$ & $\begin{array}{l}(1994) \\
\text { Zapf et al. 's } \\
\text { classification }\end{array}$ \\
\hline $\begin{array}{l}\text { Formulation } \\
\text { of intention }\end{array}$ & Mistakes & $\begin{array}{l}\text { Knowledge-based } \\
\text { mistakes }\end{array}$ & $\begin{array}{l}\text { Error in the formation } \\
\text { of intention }\end{array}$ & Intellectual level \\
\hline $\begin{array}{l}\text { Planning of } \\
\text { action }\end{array}$ & & $\begin{array}{c}\text { Rules-based } \\
\text { mistakes }\end{array}$ & & \\
\hline $\begin{array}{l}\text { Storage of } \\
\text { information }\end{array}$ & Lapses & Skill-based errors & & $\begin{array}{l}\text { Level of flexible } \\
\text { action patterns }\end{array}$ \\
\hline $\begin{array}{l}\text { Execution of } \\
\text { action }\end{array}$ & Slips & & $\begin{array}{l}\text { Error in activation } \\
\text { of schemas } \\
\text { Error in triggering } \\
\text { of active schemas }\end{array}$ & Sensorimotor level \\
\hline
\end{tabular}

GEMS $=$ generic error model system.

(execution) of an action sequence through a storage (retention) of the information. The planning involves processes that identify the goal and the ways to reach it. As an action rarely occurs directly after its planning, a storage phase (retention in memory) is generally essential between the formulation of desired actions and their execution.

- Mistakes are due to planning problems (the action is executed according to the plan and the intention, but the plan is wrong).

- Lapses result of retention deficits (the intention is not retrieved or recalled on time or at all).

- Slips are the consequences of execution problems (the plan is correct but the execution is wrong because the action is not appropriate to the intention).

An example is the action of making coffee:

- if one boils the water before putting it in the coffee-machine, it is a mistake (because the plan of making coffee is wrong);

- if one forgets that the coffee is ready or forgets to do it, it is a lapse (because the information of making coffee is not retrieved);

- if, automatically, one puts milk instead of water or makes tea instead of coffee, it is a slip (because the error is caused by an interference with a highly automatic activity).

Reason's (1990) classification accounts for cognitive processes while relating the occurrence of errors (and thus the mechanisms involved in error production) both to the degree of control (automatic behaviour vs. controlled behaviour) and to memory characteristics or even memory failures. It thus appears a helpful basis for the final elaboration of an integrated model identifying mechanisms and processes involved in error detection at various levels.

\subsection{Error detection and recovery}

Error detection and error recovery are two linked processes although the literature deals more frequently with error detection. The authors are particularly interested by the "error handling' process that can be defined as the process starting with the error detection and 
going through to the error recovery (Zapf and Reason 1994). This process sets off after the occurrence of an error and involves two stages: error diagnosis (which involves both error detection and error explanation); and error recovery (including planning and execution of the recovery action). Error detection is thus really the first step in the error handling process and is usually defined as 'the realization that an error has occurred independently from knowing what the error is like and how it came about' (Zapf and Reason 1994).

Other descriptions of the detection and recovery processes exist in the literature but the differences between them remain subtle. Detection and recovery mechanisms are usually described in the following order (Rizzo et al. 1995).

2.2.1. Mismatch between the outcome and the initial intention. This mismatch may have three sources:

- A forcing function, which stops the individual in their action and prevents them from continuing their action as long as the error is not recovered (Reason 1990).

- An external feedback, when a mismatch is suggested by information from the environment.

- An internal feedback, when a mismatch is spontaneously suggested by the individual's working memory and cannot be directly found in the environment.

The internal feedback would only permit picking out the slips, while the mistakes would be entirely signalled by limiting functions or external feedback (Sellen 1990). These observations are in line with Norman's (1981) analysis that differentiates slips detection from mistakes detection. Indeed, in the case of mistakes, there is no internal mismatch between the initial intention and the ongoing action. However, this mismatch does not always lead to a review of the actions or of the results (Rizzo et al. 1995).

2.2.2. Error detection. The person becomes aware of the error because of a strange action or outcome. The individual realizes that 'an error has occurred independently from understanding the nature and the cause of the error' (Zapf et al. 1992, Zapf and Reason 1994).

According to Reason (1990), there are three ways to detect an error:

1. The auto-control process is based on automatism and is physiologically the most effective. The errors discovered, thanks to self-detection, are recovered in to $90 \%$ of the cases (Doireau et al. 1997). This type of detection often occurs during the action execution and the error occurrence is not always picked out (the error stays at an early stage). This process is triggered by the activation of pre-attentional control mechanisms that work like immediate filters or censors of the ongoing actions. These mechanisms involve a regulation of the comparisons between the outcome and the intention (Norman 1981).

2. The environment (for example, the forcing functions may also have a role here).

3. A third person (often the only way to bring to the detection of diagnosis errors in complex and stressful situations). Woods (1984) showed that execution errors (slips) are easily detectable by operators (self-detection) but the identification of diagnosis errors require the intervention of an outsider, a 'new mind'. For example, in the diagnostic error cases, the operators involved in the action are often victims of a fixation on their schema, which prevents them changing their system state 
representation and so detecting the error (Nyssen 1997). Error detection by a third person seems not frequent (Doireau et al. (1997) obtained a rate of 30\%) but in these cases, the person who has detected the error is convinced of his judgement (and all the more so since the person is an expert, Doireau et al. 1997). In this situation, the error detection achievement depends on several factors: outsiders will detect more easily an error if they are experts in the domain; if the error is a mistake rather than a slip; and if the detection is contemporaneous of the error (Doireau et al. 1997).

2.2.3. Recovery. The individual tries to suppress or to reduce the mismatch. At this stage, he/she must know both how to recover the error effects and how to achieve the desired goal. Once the error has been detected, the recovery can actually take on two forms: either the individuals try to suppress the consequences of their error; or they try to contain them and 'manage' their error, especially in cases when the consequences are irreversible (Sellen 1990).

Recovery is certainly the less-developed point in the literature and is usually considered as the last step of the whole process. As mentioned above, it appears that an early recovery is possible. This is also confirmed by some researches on muscular contraction in choice reaction time tasks, where a correction can even take place before the error occurrence. In this case, the error is called an 'error sketch' (Smid et al. 1990) because the error is just going to appear but is corrected in time. Indeed, in choice reaction time task, Coles et al. (1985) and Eriksen et al. (1985) have observed an infraliminar contraction of the agonist muscle of the arm associated with the wrong response. This contraction occurred more often than not when the distractors were incompatible with the stimulus and the reaction time was longer when this infraliminar wrong response was observed. The error sketch is the infraliminar contraction of the agonist muscle of the wrong response preceding the correct response execution. The muscular contraction would not attain a sufficient level to produce a manifest error and the error sketch would be directly corrected, thus permitting the correct response execution. These observations show the existence of a correction process using a retroaction loop at a very early stage. Several studies have shown that, at the sensori-motor level, the participants committed ten times more error sketches than errors. All these error sketches were corrected at the proper time and allowed the execution of the correct response. These observations show the central role of recuperation in the subject performance. Further experiments could bring more information on the differences between these early recovery processes and those that operate later.

These descriptions of the 'error handling' process are as yet in the early stages and there is a lack of general agreement on this point. Sellen $(1990,1994)$ and Sellen and Norman (1992) suggested another view with the addition of a supplementary stage between error detection and error recovery: error identification. At this stage, the person compares the erroneous results with those that were expected and identifies which error has occurred. According to Sellen (1990) and Sellen and Norman (1992), the three processes are distinct and conceptually separable. It is indeed possible to detect an error without identifying it, as well as identifying an error without recovering it.

Considering that most of the authors agree that error detection occurs independently from knowing what the error is like and how it came about, the error identification process seems to be essential. Moreover, the first two stages of the description by Rizzo et al. (1995), i.e. mismatch and error detection, appear to be very similar. Indeed, they involve the same processes - the auto-control corresponding to the internal feedback, the environment corresponding to the external feedback and the forcing function. This is why 
they are associated in a single step. Another description of the global process could be the following (Sellen and Norman 1992):

- Error detection, involving mismatch.

- Error identification, i.e. knowing what the error is like.

- Error recovery, i.e. suppressing or managing the error's consequences.

\subsection{Classification of detection mechanisms}

Allwood's (1984) classification provided a first taxonomy of mechanisms supporting error detection. This study is still helpful and has offered a first and rich survey of the detection behaviours, staying however at a behavioural level. Allwood and Montgomery (1982) were the first to create experiments in which the only goal was the understanding of error detection mechanisms. They found four error detection strategies during the resolution of statistical problems:

1. Affirmative evaluation: evaluation according to the knowledge of the result (the individual evaluates their result according to what they know about the expected result).

2. Standard check: the individual controls the environment without precise suspicion and finds his/her error. It takes place independently of any feedback from obtained results or of the procedures that were adopted.

3. Direct error hypothesis formation: the individual suddenly detects and/or corrects a real or suspected error. He/she reacts to a strange result and directly forms a hypothesis on the committed error type.

4. Error suspicion: The individual is perplexed about the obtained results or the adopted procedures but he/she cannot formulate any explicative hypothesis.

The Allwood taxonomy (Allwood 1984, Allwood and Montgomery 1982) is a categorization of the types of behavioural episodes in which the detection of errors tends to occur and cannot be used as a classification of cognitive mechanisms of error detection (Sellen 1994).

Sellen (1994) and Sellen and Norman (1992) described different mechanisms involved in the error detection process, considering that errors occur at various levels in the action.

In her study, she observed four levels in which the errors can be detected.

2.3.1. Action-based detection. The individual detects the error from some aspects of the action itself (visual, proprioceptive or auditory information). This method allows the detection of the following.

2.3.1.1. Mismatches between an action plan and executed actions. For example, someone typing on a computer can know that he/she has committed a typing error without looking at the screen and without any visual feedback of the consequence. According to Rabbitt (1978), people would even be able to detect typing errors before committing them. This affirmation requires the existence of a mechanism that predicts the correctness of incipient actions rather than the correctness of the actions themselves (Sellen 1994). This is in accordance with the 'error sketching out' (Smid et al. 1990) mentioned earlier. According to Hayes and Flowers (1980), the simultaneity of error production and error detection requires the existence of cognitive mechanisms of pre-attentional control that 
immediately censor the ongoing action. This type of error detection is similar to Reason's (1990) auto-control concept.

2.3.1.2. Mismatches between conscious intentions and executed actions. For example, a person wants to make coffee and makes tea. These slips are often actions that are perfectly appropriate in other situations, i.e. with other intentions. Most of the time, only the person executing the action can detect the error. For Sellen (1994), the intentions and executed actions are temporarily disconnected and a very automatic action is executed instead of the intended action. This disconnection is made possible because the attention is directed at another event. Detection could thus occur only when the attention goes back to the initial intention. Detection occurs when the subject becomes aware that the action he/she is executing does not correspond with his/her intention.

2.3.2. Outcome-based detection. The individual detects an error through the result of the action and, more particularly, because of an unexpected result. In this case, the detection will depend on the individual's possibilities of interpreting the outcomes, but also on the experience acquired from past erroneous actions (Sellen 1994).

Three reasons can explain why the error is not detected from the action (1) (i.e. at the first stage) (2). First, the mismatch between action plan and executed actions or between intention and executed actions may not be strong enough to signal an error. Second, the intention itself can be erroneous (for example, in the case of mistakes with planning errors). Finally, the action can be correct but lead to an unexpected result.

When action-based detection fails, Sellen (1994) describes two ways of detecting errors on the basis of the outcome.

2.3.2.1. Mismatches between expected outcomes and actual outcomes. These mismatches can occur only when there are some expectations about the result of actions, when the effects of actions are perceptible, when the environment is sufficiently monitored and when the person is able to link the violation of their expectation and their actions (Sellen et al. 1990, Sellen 1994). Moreover, the expectation is related to the subject's goals that can be well specified or, on the contrary, very vague. The familiarity with the task, the domain and the nature of the task are some factors that determine the accuracy of the goal's specification. This detection process is situated both at the perceptual level and at the conceptual level.

2.3.2.2. Matches between expected error forms and outcome. The subject knows that he/ she tends to make some types of errors. Then, he/she verifies whether these errors have been committed by observing the outcomes. For example, during the month of January, a lot of people know that they tend to write the date of the previous year.

2.3.3. Detection through an external limiting function. The error is detected because the individual is blocked by physical constraints from the external environment and cannot produce any further action (for example, when someone cannot open a door because they use a wrong key). This type of detection is the same as the forcing function described earlier.

2.3.4. Detection by another person. The subject fails to detect his/her error from his/her action because he/she has monitored a wrong aspect of the action. He/she also fails to detect it from the outcome because the effects of the action were not (directly) perceptible 
and/or because the subject was not familiar enough with the domain, which made the goal not specified enough (Sellen 1994).

Sellen's (1994) taxonomy lays more emphasis on the cognitive processes. It shows the different levels at which mismatches can appear. Slips are more often detected through action, and mistakes through outcome. Indeed, slips are in conflict with intentions and can be detected either through the action or through the outcome when action-based detection has failed. On the contrary, mistakes are not in conflict with the plans and can be detected through outcome only.

However, this classification does not completely explain the cognitive process of error detection. Detection is made possible by the emergence of various types of mismatches. This emergence itself requires the existence of a mechanism assuming the comparison between the expected action (or outcome) and the actual action (or outcome). A first comparison occurs at the action level. When action-based detection fails (e.g. in the case of mistakes) a second comparison process occurs at the outcome level. When outcomebased detection also fails, only the forcing function or the discovery by another person may allow detection.

\subsection{Error detection and cerebral waves}

In the former sections, the focus has been on data concerning behavioural strategies (Allwood 1984) and cognitive mechanisms (Sellen 1994) that allow error detection. Other data come from studies on the error-related brain activity, showing the existence and the localization of some error detection mechanisms in the cortex. They reveal, in particular, the existence of two components in the event-related brain potential (ERP) associated with the error and its control.

The first is called error negativity (Falkenstein et al. 1991, 1995) or error-related negativity (ERN; Gerhing et al. 1993). This EEG wave was observed when the subjects committed an error in a choice reaction time task (Falkenstein et al. 1991). This wave seemed not to appear when the responses were correct. It was then interpreted as reflecting the occurrence of an error detection mechanism (Gerhing et al. 1993). Later, some authors have shown that the ERN also appeared with 'error sketching out' (Scheffers et al. 1996), with correct but late responses (in this case the amplitude was smaller) and also with correct responses (Luu et al. 2000, Vidal et al. 2000). Thus, the ERN would not reflect the process of error detection but rather a process of execution control that appears when the individual has a bad auto evaluation of their performance (rightly when he/she has committed an error and wrongly when their response is correct). Scheffers and Coles (2000) defined the ERN as the manifestation of a process verifying the accuracy and appropriateness of a behaviour or a response. They consider that this wave is not associated with the activation of a high-level control process. It would rather reflect a low-level monitoring process that controls the activation of specific schemes.

Falkenstein et al. (1995) and Gerhing et al. (1993) asked their participants to respond as quickly as possible and thus to favour quickness over accuracy. They observed that the ERN amplitude reduced with these orders. In fact, the ERN had a smaller amplitude when errors were made under task conditions that favoured speed over accuracy (Gerhing et al. 1993). This observation is compatible with the hypothesis of execution control: these quickness orders would incite the execution control to be less strict and thus to react to a lesser extent to errors. This would explain the reduction of the ERN amplitude. Moreover, the ERN would not reflect an objective process but a subjective error monitoring and evaluation (Luu et al. 2000) and its amplitude would depend on the 
subjective awareness of the error commission (Dehaene et al. 1994). Thus, its apparition and amplitude depend among other things on some personality factors, such as the mood or the effect (thus, the ERN amplitude is selectively related to the negative affect and the negative emotionality; Luu et al. 2000).

This wave specifically appears above the Supplementary Motor Areas (SMA) and/or the anterior cingulate cortex (Luu et al. 2000, Vidal et al. 2000). However, the exact location varies according to different studies. This is certainly due to the different nature of the tasks and to the various cognitive mechanisms and cortical areas.

Thus, the ERN does not reflect the error detection process itself. Research, however, has shown the existence of another wave called error positivity (PE) that appears after the ERN when an error has occurred (Falkenstein et al. 1991, Vidal et al. 2000). This wave does not appear when the response is correct (even late), nor when the error is in its early stages (Scheffers et al. 1996, Luu et al. 2000, Vidal et al. 2000). Thus, the PE would be specific to the committed errors (an error corrected in time is not sufficient to trigger it) and would reflect the error detection process (Vidal et al. 2000).

\subsection{Conclusion}

The classification of errors into slips/mistakes/lapses allows the distinguishing of various detection mechanisms. Slips appear to be more easily and quickly detected and recovered (Rizzo et al. 1987, see also Zapf et al. 1994 for errors at the sensori-motor level), while the detection of mistakes is rather difficult and often requires an external intervention (Woods 1984, Reason 1990), even if Doireau et al. (1997) observed the opposite in their experiments, in which the error was detected by an observer and not by the operator. In these cases, the observer who did not perform the action detected the mistakes more easily than the slips committed by the operator.

Moreover, the detection of mistakes may require more time for a lesser success. The number of slips increases significantly with the task's complexity, but so does their detection. On the contrary, the complexity of the task does not influence either the number of mistakes or their detection. The processes involved in the detection of these two types of errors might thus be different and lead to diverse detection performances. However, a specific type of slip, omissions, is more difficult to detect than any other error. All errors based on automatism (slips) are thus not always the more easily detectable errors: some omissions remain widely invisible (Reason 1990).

ERN and PE waves constitute evidence for the existence of neural mechanisms related to error. These observations show that an execution control steps in during the treatment of the sensori-motor information. This execution control would permit the detection of errors in the early stages (and would be reflected by the ERN) and would also signal that an error has just occurred (this process would be reflected by a PE wave). These observations were made in the case of execution tasks. The waves could be related to the auto-control process described by Reason (1990) and to the action-based detection proposed by Sellen (1994).

\section{Prospective memory, intention and error detection}

\subsection{Why prospective memory?}

Most errors appear to be detected because of a mismatch between the expected action (or outcome) and the actual action (or outcome). But not much is known about the 
comparison process itself. Sometimes, people think spontaneously and without any contextual factor about a previously formed intention and they realize that they did not perform it as they intended to do, or even that they did not realize their intention. Such a spontaneous error detection is related to mechanisms characterizing PM: intention persistence and recurrent intention retrievals. PM research is usually interested in these mechanisms because they support the PM performance itself by keeping the intention in mind during the retention interval. When the same mechanisms occur after the performance interval or after the task realization, they will contribute to error detection.

The concept of intention was already a core concept in the first part of this paper. This concept has been given a main place in the definition of error. Further descriptions by many authors confirm that intention is really the reference point with which ongoing action or actual outcomes are compared, thus allowing the detection of a potential error. However, its role is different in the case of slips or in the case of mistakes. A slip is an error in the execution of an intention, which brings about, in a quite direct way, a conflict between the performed action(s) and the individual's intention. A mistake is an error due to an ill-formed intention (Sellen 1994), in that case there is no conflict between action and intention.

This major role of intention, intention persistence and intention retrievals led to the investigation as to how the background of PM might enlighten the mechanisms allowing error detection. First, because the execution of an action requires the retrieval of the intention, which is the main role of PM. Second, the return of the attention to the intention is essential in order to detect slips (Sellen 1994). Finally, Reason's (1990) classification into slips/mistakes/lapses pointed out the role of consciousness and memory in error production and thus in error detection.

\subsection{Prospective memory definition and Ellis model}

Ellis (1996) described prospective remembering as 'the processing that supports the realization of delayed intentions and their associated actions...As such it is intimately associated with the control and coordination of future actions and activities'. PM was thus defined as the 'interface between memory, attention and action processes'. Fundamental research on PM thus appeared likely to provide a new enlightenment for the investigation of daily situations, including work situations, as confirmed by a first study on PM requirements by air traffic controllers (Vortac et al. 1995).

PM was defined in many different ways: from 'remembering what we must do' (Neisser 1982) or 'remembering to do something at a particular moment in the future' (Kvavilashvili and Ellis 1996) to 'realizing delayed intentions' (Ellis 1996) and as the ‘timely execution of a previously formed intention' (Kvavilashvili and Ellis 1996).

Most PM researchers suggest that the PM is responsible for the processes from intention formation to timely appropriate intention retrieval. This appropriate time may either be a well-specified time (time-based PM task) or may depend on the occurrence of a given event (event-based PM task). The PM performance is considered to be correct since the intention is appropriately retrieved, whatever happens during the realization of action(s), making thus a strict distinction between PM failure and other forms of errors (Kvavilashvili and Ellis 1996).

One may, however, consider that any error committed during the realization of an action contributes to a failure of the global PM task. This has led to considering the PM as a complex set of processes involved in the transformation of an intention into a 
'consummatory action' (Lewin 1961). As the main concern remains the detection of errors, this second viewpoint on PM will be adopted.

This viewpoint is also endorsed by Ellis who, in 1996, suggested a global model of a prospective task, which considers all phases from the 'Formation and encoding of intention and action' to 'Evaluation of outcome'. Ellis (1996) identifies the five general phases, as follows.

3.2.1. Formation and encoding of the intention and the action. At this stage, the individual forms an intention and encodes three major elements:

1. The intention (deciding to do something, the 'that element').

2. The action (what the individual wants to do, the 'what element').

3. A context that describes the circumstances and the criterion of retrieval (when the individual has to retrieve the intention and initiate the action, the 'when element').

These three elements constitute the content of the delayed intention. For example, a book is borrowed and must be returned one week later (Monday). In this case, the encoding includes the intention 'I have to', the content of the action 'give back the book' and the temporal information 'Monday'.

3.2.2. Retention interval. This interval corresponds to the time period between the encoding and the beginning of an eventual performance interval. In the example, this interval lasts $7 \mathrm{~d}$. During this interval, the intention can be retrieved and refreshed by spontaneous mechanisms or by external cues.

3.2.3. Performance interval. During this period, the encoded intention has to be retrieved at least once and the action performed. Moreover, the actual situation has to be identified as reflecting the initially established context of recuperation (the 'when element'), associated with the specific intention (the 'that element') and finally associated with the intended action (the 'what element'). In the example, the performance interval lasts $1 \mathrm{~d}$ (Monday).

3.2.4. Initiation and execution of the intended action. The action is executed. In the example, the person picks up the book and gives it back to the library.

3.2.5. The outcome evaluation. The action outcome is here evaluated in order to check whether the action has been executed as intended. The existence of this last phase is also one of the PM issues that has motivated the attempt to link error detection with PM. Ellis (1996) justifies it with the necessity of some form of outcome record in order to avoid the repetition of a satisfied intention or to ensure the success of a postponed or failed delayed intention (i.e. avoiding the omission). One may also think that it is a key phase in which the subject may compare the actual outcome with the expected one and thus detect at least a deviation. However, the objective of this study is to go one step further by admitting that this phase may actually last quite a long time, until the actual resumption of the intention, i.e. until the individual feels, even subjectively, that his/her intended goal has been achieved.

Further investigation on the recording function itself, or 'output monitoring', (Koriat and Ben Zur 1988, see also Kvavilashvili and Ellis 1996, for a first analysis of the relation to errors) might also provide interesting leads for understanding the cognitive dissonance or the 'feeling of uncompleted task' that is often the first step towards error detection. At 
the junction point between memory and action control, Koriat et al. (1990) studied the processes involved in recording and distinguishing the performed actions from the actions to be performed. These processes may be twofold:

1. A real-time marking of the performed task, deleting the intention. In the same way that one tears up a written note, one can imagine an internal process erasing the intention from a 'mental scratch pad'. This on-line process is close to Lewin's (1961) notion of tension discharge and also to Reason's (1990) notion of a programme counter for checking off actions as they are executed. According to Dockree and Ellis (2001), the process of cancelling the intention may be regulated by the supervisory attentional system described by Norman and Shallice (1986).

2. A retrospective evaluation provoked by another opportunity in order to realize the intention, either through the apparition of contextual factors or through a spontaneous retrieval. In such cases, the individual has to scrutinize his/her memory (or an external memo pad) looking for evidence that the intention has been executed.

Potential failure modes of this function offer a compromise between memory failures and errors, explaining errors related to the repetition or the omission of actions. In these cases, the intention is correctly retrieved, but its status (realized or not yet realized) has been forgotten. Deficient output monitoring may result in:

- a failure to perform the act, due to a mistaken belief that it has already been performed;

- a repetition of the act, due to a false belief that it has not been performed;

- checking to make sure that it has been performed, in case of uncertainty.

An earlier study by Wilkins and Baddeley (1978) showed less action repetitions than action omissions. For Reason (1984), repeating planned acts is also infrequent among action slips. This could be related to the 'reality monitoring', i.e. 'how a person decides whether he has performed an act or has only imagined it'. For Koriat et al. (1990), 'it would appear that a failure to perform an act should be more likely when it is contemplated and planned in detail in advance'.

Considering the variety of external supports, one could suspect a wide variability in internal processes. For Koriat and Ben Zur (1988), there is however 'no conclusive evidence that prospective plans are cancelled or tagged on-line upon completion'. On-line cancellation is apparently not perfect, which explains this feeling of having forgotten (this is the first step towards detection). In these cases, individuals may 'create' supplementary checking opportunities for themselves. Regarding retrospective monitoring, it appears that people questioned about a performed action tend to check its performance through the action's result (sugar in the coffee) rather than by scrutinizing their memory on the action itself.

Further studies on this output monitoring processes could thus provide explanations of error detection mechanisms by explaining why and how intentions remain in the memory, especially why a person will go on thinking of an intention even when he/she has performed the corresponding action:

- A wrong marking of the intention.

- More subtle marking for uncompleted or interrupted actions, or even for miscompleted actions. 


\subsection{Intention}

Some philosophers tend to define human behaviour as a set of events caused by intentions (Harré 1982, Brand 1984), but it remains difficult to define what an 'intention' is. Intentions are different from retrospective memories, both for what concerns their representations as for their status. Intentions may be retrieved and have to be activated at any time (Hicks et al. 2000). They are thus stored in memory with specific characteristics and they have a particular status in the memory. Some experimental and neuropsychological evidence seems to be emerging from the literature, suggesting that an intention is encoded under a functionally different form than the other memories and the stored representations of an intention may reside in memory under a privileged status (Shallice and Burgess 1991, Gsochke and Kuhl 1993, Marsh et al. 1998a, 1999). That special dynamic status may be a relatively higher activation level compared with neutral memories with a quicker than average revival rate when being retrieved, this is named the intention superiority effect (ISE) (Marsh et al. 2002). The ISE is characterized by faster response time to task material intended for future performance than for neutral material with no associated intention or material that is linked to a cancelled intention (Goschke and Kuhl 1993, Dockree and Ellis 2001).

In order to cover the diversity of intentions, Kvavilashvili and Ellis (1996) gave a flexible definition as 'a person's readiness to act in a certain way in the future, where what has to be done and when it has to be done are defined with more or less clarity'. Compared to other definitions this one focuses on the that/what/when aspects (see Ellis 1996) rather than the who/where/how components, considered as further specifications of the former. The way these components interact with each other and their relative importance in intention forming will lead to a representation of the intention. Moreover, this representation may evolve according to constraints or events intervening during the retention interval, thus provoking successive attempts for re-encoding the intention. It is here possible to detect and correct some kinds of ill-formed intentions. For example, one may retrieve an intention and realize that it is in conflict or not compatible with previously scheduled constraints. An intention may also be modified because the associated consummatory action is not really satisfying: 'phone mother' may be replaced by 'write to mother' without any specific external constraint.

For Ellis (1996) and Mantyla (1996), forming an intention allows a sensitivity to specific external cues, depending on the relative importance of the intention's components. Lewin (1961) also considered that when an individual forms an intention, objects and events in their environment acquire what he calls a 'valence' in relation to this intention. This sensibility (or valence) is specific for each individual and may also play a specific role in the production of errors, as well as in their detection. An excessive accuracy of the cues associated with the intention may cause the prevention of the fulfilment of the intention with a substitute action, while it could make the detection easier. On the contrary, an intention showing a small dependency to external cues may lead to premature acts or to action performance when the situation is not appropriate, with few possibilities for detecting it.

Further distinctions have been made among intentions. Searle (1983) distinguished prior intentions, which are the result of a conscious decision to act in a certain way (see e.g. Brand 1984, Heckhausen and Kuhl 1985, Nuttin 1987) and intentions-in-action (spontaneous action, not associated with a prior intention). Prior intentions may be carried out immediately after the decision (immediate intentions) or be postponed (delayed intentions). While PM research usually focuses on the latter, the various types of 
intentions will be considered. Indeed, these distinctions actually reflect the relationship between memory, intention and action, as well as the role of consciousness in the development of an intention, i.e. precisely the factors supposed to have an influence on the possibility of detection.

Lewin (1961) suggested a theory, according to which the intention, once formed, is like a need that requires to be satisfied. Forming an intention thus creates a tension that needs to be released. Lewin (1961) notices, however, that the satisfaction of an intention is not fully related to its representation (e.g. the intention to write to a friend may be satisfied by an opportunistic phone call. In that case, one may suppose that the 'right' intention was to contact this friend). He thus creates the concept of a 'substitute action', or an 'action appropriate to the situation', i.e. an action allowing the intention's satisfaction, different from the initial one. The means for the intention's resumption emerge here from the concrete situation. This is close to the more recent concept of 'opportunistic planning'. This concept of substitute action actually supports the hypothesis that an individual has a natural tendency to satisfy their intentions and thus a tendency to detect non-satisfied intentions.

\subsection{Intention retrievals: what brings intentions to mind}

Intention retrievals occur both during the retention interval (keeping the intention in mind until the performance interval) and after the supposed realization of the intention. Most people have indeed already shouted: 'I forgot to buy some bread', 'I have not finished writing this letter', 'I have signed the wrong paper' quite a long time after the described action and apparently without any external cue. In such cases, error detection is due to a spontaneous retrieval of the intention after its supposed realization.

Most authors of PM consider two kinds of mechanisms bringing intentions to mind:

1. Outside-in retrievals are contextual and triggered by an element, a person or an event in the environment that was associated with the intention, or at least with its representation. There is a huge variety of external factors likely to remind people of an intention, sometimes the associations are quite surprising because they depend on each person's experience or personality. For example, seeing a bank may remind an individual that he/she has a financial operation to perform, while seeing a bank will remind someone else that he/she has to phone his/her brother (who is a banker).

2. Inside-out retrievals, the intention comes to mind without any external cue. In these cases, one may suppose the existence of an internal mechanism bringing intentions to mind, more or less regularly and during a given period of time. Some authors evoke here a kind of internal marker met from time to time by a wandering thinking. Another alternative would be a subject's control on retrieval initiation, particularly on their frequency. It then appears that intentions are alternatively conscious and unconscious, coming across a kind of threshold. As emphasized by Einstein and MacDaniel (1996), 'one of the most salient features of PM retrieval is that it often occurs spontaneously and without conscious attempts to interrogate memory'. In the introduction of Prospective Memory: Theory and Applications (Brandimonte et al. 1996), the authors pointed out that the 'prospective memory may provide new and interesting avenues for examining issues related to implicit or non-conscious retrieval'.

In both cases, the attention is strongly involved as these retrievals occur when participants perform tasks requiring more or less attention. The attention dedicated to 
another activity may reduce sensitivity to contextual factors or directly interfere with an internal control process. The Simple Activation Model (Einstein and MacDaniel 1996) identifies interactions between these two different kinds of mechanisms. In this model, the representation of an intention creates and activates an association between action and cues. The activation level of these associations remains below a 'conscious awareness' threshold and keeps decreasing as long as the subjects are involved in other activities, unless a reactivation through contextual factors or thoughts is initiated in an internal way (intention retrievals). Ellis (1996) also emphasizes that the role of these 'recollections of delayed intentions' is multiple. They may refresh or reinforce the intention in memory by re-increasing the activation level but they also provide opportunities for reformulating or modifying the intention, thus facilitating not only an opportunistic behaviour but also the recovery of ill-formed intentions.

An in situ study (Sellen et al. 1996) focuses on these intention retrievals. Participants were assigned two kinds of PM tasks: time-based; and event-based. Furthermore, they were required to signal (using an electronic badge) each time they remembered the corresponding intention. Such a protocol allowed the recording, not only at what time the participants remembered their intention, but also in which conditions (place, activity, etc.)

This study provided some interesting results. The number of retrievals evolves with time: the experiment was conducted during a whole week, a decrease of this number of retrievals was noticed. This may be due to a decrease in the motivation or to tiredness, but one may also interpret it as a learning process leading to an efficient number of retrievals, i.e. a number both necessary and sufficient. It has also been noticed that intention memories are more often due to contextual factors than to spontaneous or controlled retrievals. Little by little, participants may create associations, which are likely to help them to retrieve their intention. Results on the non-randomness of retrievals also suggest a participant's partial control on inside-out retrievals (at least on their frequency). The conscious nature of retrievals also appears in the interviews 'make myself aware of the task', 'keep the task in mind'.

\subsection{Intention persistence}

A main characteristic of PM tasks and one of the motivations for relating PM and error detection is the persistence of intentions, or what Lewin (1961) called the intentioneffect'. The question, however, remains: 'Why, how and how long do intentions persist, even after their realization?'. According to Goschke and Kuhl (1993), persisting activation of the intention should have especially an adaptive role in time-based tasks for which any external cue can help to remember the prospective task.

In the experiment conducted by Sellen et al. (1996), the distribution of retrievals can be compared to the occurrence of task opportunities: subjects think of their intention both before and after opportunities (less after); and the retrieval probability before or after a failure (not realizing the task in spite of an opportunity to do it) is smaller than the retrieval probability before or after a success. Marsh et al. (1998a, 1999) showed a heightened activation of intention prior to performance and an intention inhibition effect after its completion.

Other experiments show that longer retention intervals could induce a better PM performance (Marsh et al. 1998b, Hicks et al. 2000). During this retention interval, the PM performance first follows the forgetting curve $(2 \mathrm{~min})$ and then increases. This might be explained by the fact that longer intervals allow both a greater number and a greater 
regularity of intention retrievals (refreshment of the intention). These studies also show the role of 'breaks' between two activities.

In the experiment by Sellen et al. (1996), the authors investigated whether some places were more favourable to intention retrievals. They were also led to differentiate between places being associated with an activity and other places, called transition places. These transition places are, for example, corridors or any location between two activity places; they are not associated with a particular activity and are probably related to the 'breaks' mentioned above. Park et al. (1997) also showed that concurrent activity had more impact on an event-based prospective task than on a time-based task and emphasized the importance of the ongoing activities in explaining PM performances. This series of experiments thus suggest that activity-based PM, i.e. when the appropriate time is defined by the end of an activity, should be a supplementary component in the usual classification, in addition to time-based and event-based tasks.

It has been shown that error detection is due to the occurrence of intention retrievals after the appropriate time for action execution. One may thus suppose that the effective intention realization is not the only criterion for suppressing this intention from the set of to-be-performed actions. More particularly, the objective realization is not always associated with a subjective feeling of goal achievement. In studies on task interruption, Mantyla (1996) echoes Zeigarnik's (1927) viewpoint, i.e. that the crucial factor is not the objective completion or interruption of a task but rather a subjective feeling of having finished a task or, on the contrary, of being unsatisfied:

a quasi-need persists if the task has not been completed to the subject's own satisfaction regardless of whether this is equivalent to what may seem from another person's inspection to constitute 'finished' or 'unfinished'. Tasks with whose solution the subject is not content will function in his memory as 'unfinished' even though the experimenter may have classified them as completed and vice versa.

Lewin (1961) also observed quite early on how the 'intention-effect' may manifest itself through a tendency to complete interrupted activities without requiring an external stimulus and sometimes after relatively long intervals: 'there is still something to be done'. Indeed, Goschke and Kuhl (1993) obtained results that provide clear support for Lewin's persistence hypothesis and developed the concept of ISE showing that intentions produce a persisting 'task tension' leading to superior recall of incomplete activities (Zeigarnik 1927, Goschke and Kuhl 1993).

\subsection{Episodic actions vs. habitual actions}

Most PM studies concern experimental tasks, dealing with the capacity to remember an exceptional intention. It is thus not clear whether their results on PM characteristics remain valid for the persistence of intentions related to habitual actions (Meacham and Leiman, 1982). The role of intention itself in the performance of habitual actions is probably quite different from its role in the performance of episodic actions. People are, however, susceptible to commit errors, including omission, in both types of actions. Moreover, this distinction is a major point in the case of routine errors.

As already evoked in the in situ study by Sellen et al. (1996), Meacham and Leiman (1982) supposed that retrievals of habitual actions rely progressively more on associations with contextual factors and more particularly in relation to another activity. These associations would build up through successive realizations of the action. Ellis (1996) 
emphasized that the robustness of these connections will precisely distinguish habitual actions from episodic actions. A strategy for remembering episodic actions more easily is thus to integrate them in the course of habitual actions. Lewin (1961) also considered that learning modifies the valence of objects and events with regard to intentions.

Among episodic actions, one may again distinguish between the tasks to be retrieved only once and the tasks to be retrieved several times. The latter seem to be an intermediate, but necessary, step in the transformation of an episodic action into an habitual one. In a diary study Andrzejewski et al. (1991) showed the importance of these repeated episodic intentions: for example, the probability to retrieve an appointment increases with the number of realized appointments. It remains, however, difficult to know whether the influencing factor is the frequency of the action realization or its regularity. Further investigations should thus concern the role of this progressive contextualization of intentions on error detection and whether detection mechanisms are different for episodic action and for habitual ones.

\subsection{Prospective memory and frontal lobes}

$\mathrm{PM}$ is the memory for future actions and is thus much less tractable in the laboratory (Baddeley and Wilkins 1984). Most authors adopt the position that PM is not unitary and involves different processes underlain by different brain structures (Glisky 1996, Palmer and McDonald 2000). Some cognitive mechanisms involved in prospective remembering are self-directed planning, organization, sustained attention, concentration, inhibition process and retrospective memory. In fact, PM tasks include both retrospective and prospective components (Kvavilashvili 1987, Einstein and McDaniel 1990, Brandimonte and Passolunghi 1994, Ellis 1996). Therefore, some PM processes are similar to those involved in retrospective memory, while others have to be specific to PM and controlled by the frontal cortex.

The frontal lobes are the last developed cerebral area during phylogenesis and ontogenesis, but they are also the largest. They support the highest levels of cognitive functioning, called executive functions. They are morphologically complex and richly connected to every other area in the brain. They are required for language, planning and monitoring non-routine activities, problem-solving, initiating activity, monitoring and evaluating behaviours and outcomes. For example, they play an organizational and strategic role in memory tasks, they help to organize recall, find the right cue, etc. Moreover, the prefrontal cortex seems to play an important role in the activation of memories and in the maintenance of the relevant representations and activities.

All these functions of frontal lobes are necessary for an effective PM functioning. In fact, PM involves the formation and the organization of intentions, the intention recall during a lapse of time, the monitoring of the way to execute action and, finally, the action execution and the recollection of having done it (Bisiacchi 1996). All these abilities require the activation of frontal lobes. Furthermore, the intended action has to be initiated and frontal lobes are responsible for the initiating activity. This activation occurs either from environmental stimulus (as in the event-based tasks) or spontaneously without cue in the environment (as in the time-based tasks). Time-based prospective remembering is assumed to be more difficult because it requires more self-initiated retrieval processes (and thus more involvement of frontal lobes) than event-based prospective remembering. This is the well-known difference between the time-based and event-based tasks (Einstein and McDaniel 1990). Indeed, people with frontal lesions or the elderly (in the ageing process, the frontal lobes are the first cerebral area affected) are 
particularly in trouble in time-based tasks while they quasi normally perform in eventbased tasks (Shapiro et al. 1998).

The inhibition process is another executive function and also depends on the frontal lobes. PM requires the intervention of an inhibition mechanism (Kerns 2000). In fact, the reflexes and the dominant behaviours have to be inhibited in order to maintain the relevant representations active and so to achieve the fixed goal. In PM tasks, the competitive behaviours that are not appropriate are inhibited and the ongoing behaviour often has to be stopped to allow the execution of the intended action (Cohen and O'Reilly 1996). For example, when one goes back home, one has to stop the car to re-fuel or to go shopping. One has to stop an ongoing or a usual behaviour in order to perform an intended action, which is unusual or not quite usual. The inhibition process is thus very important for PM performance. Indeed, PM failures are notably caused by interference with interpolating activities (Brandimonte and Passolunghi 1994).

Finally, the monitoring process also depends on the frontal lobes. Thus, outcome evaluation, the ultimate phase in Ellis' model, involves the activation of the frontal lobes. Therefore, error detection, which can ensue from this evaluation, implies the intervention of the frontal lobes.

\section{Detection model}

Following these overviews on error detection and PM, a preliminary model of error detection summarizing the various concepts mentioned may be presented as follows. As seen in figure 1, it is based on the chronology defined by Ellis' model for a PM task.

Intention formation may lead to ill-formed intentions, i.e. mistakes. These mistakes may then be detected and re-formulated during the retention interval, following intention retrieval. Otherwise, their detection will be possible only after an error occurrence when the outcome is not correct. Intention retrievals occurring during the performance interval provoke the action initiation, leading either to an 'error sketching out' (i.e. immediately

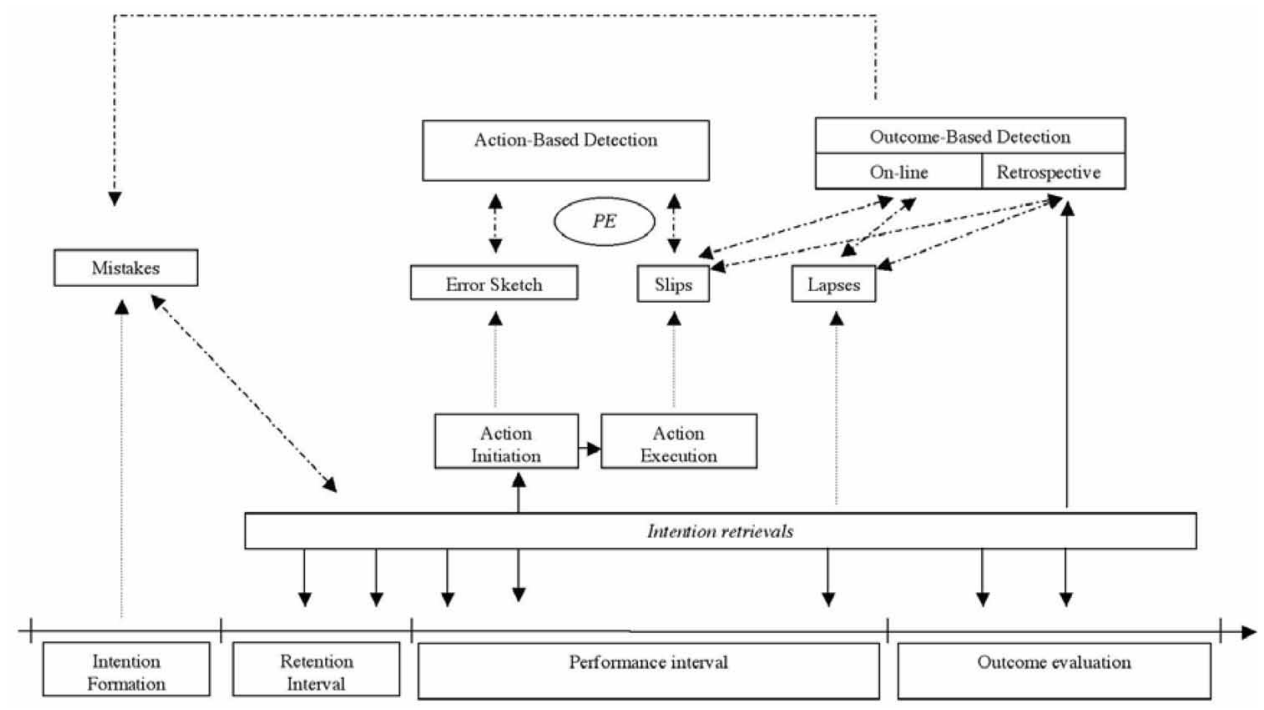

Figure 1. Error detection model from Ellis prospective memory model. PE = error positivity. 
detected and corrected) or to action execution. Slips may occur during action execution and may be detected either through action-based or through outcome-based detection. When an action is not initiated during the performance interval it is a lapse, detected only through outcome-based detection. Intention retrievals occurring after the performance interval provoke a retrospective evaluation of the action and outcome, thus allowing for further detection possibilities.

\section{Final conclusion}

The choice of Reason's (1990) classification into lapses/mistakes/slips allowed the investigation of parallel existing studies on error detection and research concerning various aspects of PM. Thus, it could be pointed out that various mechanisms are taking part in the detection of the different types of errors, while identifying, at the same time, transversal issues. First, a major relationship with intention, both for error production and for error detection; second, a general possibility to identify action-based detection and outcome-based detection. Slips appear to be more easily detectable than mistakes, while omissions - specific kinds of lapses - seem to require a separate analysis. Finally, this classification is based on the individual's role in error production. The subjective component involved in error detection has also been emphasized both by researches on PM and intention theory and by data on cerebral waves (ERN and PE).

The first overview of the relationships between PM (and more generally the theory of intentions) and error detection raises some questions likely to support further studies. The usual classification of PM tasks into time-based and event-based tasks could provide a canvas for the identification of detectable errors (vs. undetectable errors) as well as for the different mechanisms involved in the detection. Combined with knowledge on outputmonitoring, this classification could also be enriched by the notion of the activity-based task that was, until now, considered too close to the event-based task and by the mode of task management, distinguishing between active tasks and passive tasks. This distinction, already evoked by Lewis (1997), could maybe be related to the 'personality regions' concept (Lewin 1961).

As mentioned before, the output monitoring function could be investigated more deeply, especially as far as the status of interrupted, uncompleted or even mis-completed tasks are concerned.

Regarding intention retrievals occurring after action realization, it would be interesting to study whether their nature and frequency are related to the way the task has been performed, including the case of action omission. Another point is the duration of the interval during which retrievals occur after the action. Is this duration dependent on the retention interval? Is it task-dependent? Is it a constant? Following the hypothesis of a very early unconscious detection, one could also suggest that these retrievals are fully suitable to favour detection. This could also be related to Lewin's (1961) theory, postulating that individuals look for each opportunity to satisfy the intention.

More generally, it also appears necessary to study the role of personality variables (attentional abilities, motivational aspects) explaining why an intention becomes important for an individual, thus allowing its persistence and maybe the detection of associated errors. Indeed, it appears that PM performance is strongly related to the importance that someone can attach to the intention (Cicogna and Nigro 1998) and this may be due to specific variables that remain difficult to control.

Even if the localization is not perfectly known, EEG waves appear in frontal regions and concepts mentioned in these prospective issues appear to be strongly related to the 
functioning of frontal lobes, responsible for planning, inhibition of competitive behaviours, action initiation and monitoring of behaviours and outcomes. First, a slip is detected when the attention goes back to the initial intention or plan. This change in the attention focus is permitted by the intervention of the frontal lobes. Sometimes, slips are caused by the non-inhibition of a routine activity that is executed instead of the intended unusual action. These slips could be due to a bad functioning of the frontal lobes, while their detection occurs when a correct intervention of the frontal lobes allows the monitoring of a behaviour or outcome.

Second, a mistake is due to an ill-formed intention. The frontal lobes are responsible for planning activities and formulating plans. They are thus at the origin of the mistake, but they are also involved in error detection by allowing the outcome evaluation.

Moreover, the plans show the way that the automatic activation has to follow. They play the role of a guide. They constitute a solid base for the detection and recuperation of errors (Doireau et al. 1997, Scheffers and Coles 2000). Patients with frontal lesions often have trouble in planning and/or sustaining attention. The behavioural pattern looks like slips occurring in healthy persons (Reason 1990).

These preliminary investigations have encouraged the desire to give a greater place to the detection of errors, which is a way to recognize the positive and formative role of errors. Detecting his/her own errors is indeed what characterizes the expert. The capacity to detect and recover errors is often considered as the transition from a novice stage to a stage of deeper knowledge (Adams and Goetz 1973). Allwood (1984) also showed that the individual's performance is not characterized by the frequency of errors, but rather by the person's efficiency in detecting these errors. For Amalberti (1996), the best participants are not the ones who do not commit any error, but the ones who detect their errors. Most teachers could say the same, both about their best pupils and about themselves. This could be explained by the greater possibility for an expert to dedicate attentional resources to error detection when he/she is involved in a familiar task.

Earlier authors have already underlined that teaching and training programmes should include detection and recovery techniques as well as error prevention (Reason 1990), whilst also stressing the importance of favouring a spontaneous detection by operators (De Keyser and Nyssen 1993). Indeed, the error is not to be considered only under a negative aspect (Wehner and Stadler 1994). Making errors plays a part in learning and in the adaptation processes. In learning processes, the errors delay the transition towards the automation of a new skill and they allow the re-evaluation of already automated skills (Reason 1990). Following a biological and evolutionist theory of error, Hasbroucq et al. (2000) considered error as a means for the individual to generate, discover and select new behaviours more likely to be adapted to further situations. Moreover, errors may stimulate creativity and the adoption of new exploratory strategies (Reason 1990).

\section{Acknowledgements}

This work was supported by grants from the National Funds for Scientific Research and from the Inter University Attraction Poles (contract no. P4/19)

\section{References}

Adams, J.A. and Goetz, E.T., 1973, Feedback and practice as variables in error detection and correction. Journal of Motor Behavior, 5, 217-224.

Allwood, C.M., 1984, Error detection processes in statistical problem solving. Cognitive Science, 8, $413-437$. 
Allwood, C.M. and Montgomery, P., 1982, Detection of errors in statistical problem solving. Scandinavian Journal of Psychology, 23, 131-139.

Amalberti, R., 1996, La Conduite des Systèmes à Risques (Paris: Presses Universitaires de France).

Andrzejewski, S.J., Moore, C.M., Corvette, M. and Herrmann, O., 1991, Prospective memory skill. Bulletin of Psychonomic Society, 29, 304-306.

Baddeley, A.D. and Wilkins, A., 1984, Taking memory out of the laboratory. In Everyday Memory, Actions and Absent-Mindness, J.E. Harris and P.E. Morris (Eds.), pp. 1-17 (New York: Academic Press).

Bisiacchi, P.S., 1996, The neuropsychological approach in the study of prospective memory. In Prospective Memory: Theory and Applications, M. Brandimonte, G.O. Einstein and M.A. McDaniel (Eds.), pp. 297-318 (Mahwah, NJ: Erlbaum).

Brand, M., 1984, Intending and Acting: Toward a Naturalised Action Theory. (Cambridge, MA: MIT Press).

Brandimonte, M. and Passolunghi, M.C., 1994, The effects of cue-familiarity, cue-distinctiveness and retention interval on prospective remembering. The Quarterly Journal of Experimental Psychology, 47, 565-587.

Brandimonte, M., Einstein, G.O. and McDaniel, M.A., 1996, Prospective Memory: Theory and Spplications. (Mahwah, NJ: Lawrence Erlbaum Associates).

Cicogna, P.C. and Nigro, G., 1998, Influence of importance of intention on prospective memory performance. Perceptual and Motor Skills, 87, 1387-1392.

Cohen, J.D. and O'Reilly, R.C., 1996, A preliminary theory of interactions between prefrontal cortex and hippocampus that contribute to planning and prospective memory. In Prospective Memory: Theory and Applications, M. Brandimonte, G.O. Einstein and M.A. McDaniel (Eds.), pp. 267-296 (Mahwah, NJ: Erlbaum).

Coles, M.G.H., Gratton, G., Bashore, T.R., Eriksen, C.W. and Donchin, E., 1985, A psychophysiological investigation of the continuous flow model of human information processing. Journal of Experimental Psychology: Human Perception and Performance, 11, 529-553.

Dehaene, S., Posner, M.I. and Tucker, D.M., 1994, Localization of a neural system for error detection and compensation. Psychological Science, 5, 303-305.

De Keyser, V. and Nyssen, A.S., 1993, Les erreurs humaines en anesthésie. Le Travail Humain, 56, $243-266$.

Dockree, P.M. and Ellis, J.A., 2001, Forming and cancelling everyday intentions: Implications for prospective remembering. Memory and Cognition, 29, 1139-1145.

Doireau, P., Wioland, L. and Amalberti, R., 1997, La détection d'erreurs humaines par des opérateurs extérieurs à l'action: Le cas du pilotage d'avion. Le Travail Humain, 60, 131-153.

Einstein, G.O. and Mc Daniel, M.A., 1990, Normal aging and prospective memory. Journal of Experimental Psychology: Learning, Memory, and Cognition, 16, 717-726.

Einstein, G.O. and MC DANiEL, M.A., 1996, Retrieval processes in prospective memory: Theoretical approaches and some new empirical findings. In Prospective Memory: Theory and Applications, M. Brandimonte, G.O. Einstein and M.A. McDaniel (Eds.), pp. 115-141 (Mahwah, NJ: Erlbaum).

Ellis, J., 1996, Prospective memory for the realization of delayed intentions: A conceptual framework for research. In Prospective Memory: Theory and Applications, M. Brandimonte, G.O. Einstein, and M.A. McDaniel (Eds.), pp. 1-23 (Mahwah, NJ: Erlbaum).

Eriksen, C.W., Coles, M.G.H., Morris, L.R. and O'Hara, W.P., 1985, An electromyographic examination of response competition. Bulletin of the Psychonomic Society, 23, 165-168.

Falkenstein, M., Hohnsbein, J. and Hoorman, J., 1991, Effects of crossmodal divided attention on late ERP components: II. Error processing in choice reaction time tasks. Electroencephalography and Clinical Neurophysiology, 78, $447-455$.

Falkenstein, M., Hohnsbein, J. and Hoorman, J., 1995, Event-related potentials correlates of errors in reaction tasks. In Perspectives of Event-Related Potentials Research, G. Karmos, M. Molnar, V. Csepe, I. Czigler and J.E. Desmedt (Eds.), pp. 287-269 (Amsterdam, Elsevier).

FrESE, M., 1991, Error management or error prevention: two strategies to deal with errors in software design. In Human Aspects in Computing: Design and Use of Interactive Systems and Work with Terminals, H.J. Bullinger (Ed), pp. 776 - 782 (Amsterdam: Elsevier Science).

Gehring, W.J., Goss, B., Coles, M.G.H., Meyer, D.E. and Donchin, E., 1993, A neural system for error detection and compensation. Psychological Science, 4, 385-390.

Glisky, E.L., 1996, Prospective memory and the frontal lobes. In Prospective Memory: Theory and Applications, M. Brandimonte, G.O. Einstein and M.A. McDaniel (Eds.), pp. 249-266 (Mahwah, NJ: Erlbaum).

Goschke, T. and Kunl, J., 1993, Representation of intentions: Persisting activation in memory. Journal of Experimental Psychology: Learning, Memory and Cognition, 19, 1211-1226.

Grant, S., 1997, Cognitive architecture for modelling human error in complex dynamic tasks. Le Travail Humain, 60, 363-385. 
Harré, R., 1982, Theoretical preliminaries to the study of action. In The Analysis of Action: Recent Theoretical and Empirical Advances, M. von Cranach and R. Harré (Eds.), pp. 5-34 (Cambridge: Cambridge University Press).

Hasbroucq, T., Vidal, F., Burle, B., Bonnet, M. and Possamaï, C.A., 2000, Arguments physiologiques en faveur d'un contrôle d'exécution au cours d'activités sensori-motrices sous contrainte temporelle, Communication présentée au Séminaire sur le Risque de Défaillance et son Contrôle par les Individus et les Organisations dans les Activités à Hauts Risques, Première séance, 30-31 mars, Gif-sur-Yvette.

HAYes, J.R. and Flower, L.S., 1980, Identifying the organization of writing processes. In Cognitive Processes Writing, L.W. Gregg and E.R. Steinberg (Eds.), pp. 3-30 (Hillsdale, NJ: Erlbaum).

Heckhausen, H. and Khul, J., 1985, From wishes to action: The dead ends and short cuts on the long way to action. In Goal-directed Behavior: Psychological Theory and Research on Action, M. Frese and J. Sabini (Eds.), pp. $134-160$ (Hillsdale, NJ: Erlbaum).

Hicks, J.L., Marsh, R.L. and Russel, E.J., 2000, The properties of retention intervals and their affect on retaining prospective memories. Journal of Experimental Psychology: Learning, Memory and Cognition, 26, $1160-1169$.

Hollnagel, E., 1998, A Cognitive Reliability and Error Analysis Method: CREAM. (Oxford: Elsevier).

KERnS, K. A., 2000, The cybercruiser: An investigation of development of prospective memory in children. Journal of International Neuropsychological Society, 6, 62-70.

Kirwan, B., 1998, Human, error identification techniques for risk assessment: Part 1 : Overview of approaches. Applied Ergonomics, 29, 299-318.

Koriat, A. and Ben Zur, H., 1988, Remembering that I did it: Processes and deficits in output monitoring. In Practical Aspects of Memory. Current Research and Issues, M.M. Gruneberg, P.E. Morris and R.N. Sykes (Eds.), vol. 1, pp. 203-208 (Chichester: Wiley).

Koriat, A., Ben Zur, H. and Nussbaum, A., 1990, Encoding information for future action: memory for to-beperformed tasks versus memory for to-be-recalled tasks. Memory and Cognition, 18, 568-578.

Kvavilashvili, L., 1987, Remembering intentions as a distinct form of memory. British Journal of Psychology, 78, 507-518.

Kvavilashvili, L. and Ellis, J., 1996, Varieties of intentions. In Prospective Memory: Theory and Applications, M. Brandimonte, G.O. Einstein and M.A. McDaniel (Eds.), pp. 23-51 (Mahwah, NJ: Erlbaum).

LePlat, J., 1985, Erreur Humaine, Fiabilité Humaine dans le Travail (Paris: Armand Colin).

LewIN, K., 1961, Intention, will and need. In Classics in Psychology, T. Shipley (Ed.), pp. 1234-1288, Original work published in 1926 (New York: Philosophical Library).

LewIS, K., 1997, Prospective memory as a goal-directed activity: An alternative classification to a time and event distinction. Prospective Memory Workshop, University of Leuven, Belgium, 23-24 May 1997.

Luu, P., Flaisch, T. and Tucker, D.M., 2000, Medial frontal cortex in action monitoring. Journal of Neuroscience, 20, 464-469.

Mantyla, T., 1996, Activating actions and interrupting intentions: Mechanisms of retrieval sensitization in prospective memory. In Prospective Memory: Theory and Applications, M. Brandimonte, G.O. Einstein and M.A. McDaniel (Eds.), pp. $93-113$ (Mahwah, NJ: Erlbaum).

MARSh, R.L., Hicks, J.L. and BinK, M.L., 1998a, Activation of completed, uncompleted and partially completed intentions. Journal of Experimental Psychology: Learning, Memory and Cognition, 24, 350-361.

Marsh, R.L., Hicks, J.L. and LANDAU, J.D., 1998b, An investigation of everyday prospective memory. Memory and Cognition, 26, 633-643.

Marsh, R.L., Hicks, J.L. and Bryan, E.S., 1999, The activation of unrelated and cancelled intentions. Memory and Cognition, 27, 320-327.

MARSh, R.L., Hicks, J.L. and WATSON, V., 2002, The dynamics of intention retrieval and coordination of action in event-based prospective memory. Journal of Experimental Psychology: Learning, Memory and Cognition, 28, $652-659$.

Meacham, J.A. and Leiman, B., 1982, Remembering to perform future actions. In Memory Observed: Remembering in Natural Contexts, U. Neisser (Ed.), pp. 327-336 (San Francisco: Freeman).

Neisser, U., 1982, (Ed.) Memory Observed: Remembering in Natural Contexts. (San Francisco: Freeman).

Norman, D.A., 1981, Categorization of actions slips. Psychological Review, 88, 1-15.

Norman, D.A. and Shallice, T., 1986, Attention to action: Willed and automatic control of behavior. In Consciousness and Self-Regulation, G.A. Schwartz and D. Shapiro (Eds.) (New York: Plenum).

NutTin, J.R., 1987, The respective roles of cognition and motivation in behavioral dynamics, intention and volition. In Motivation, Intention and Volition, F. Halisch and J. Kuhl (Eds.), pp. 309-321 (Berlin: SpringerVerlag). 
NysSEN, A.S., 1997, Une nouvelle approche de l'erreur humaine dans les systèmes complexes: Exploration des systèmes complexes en anesthésie, Thèse de doctorat en Psychologie, non publiée, Université de Liège, Liège.

Palmer, H.M. and McDonald, S., 2000, The role of frontal and temporal lobe processes in prospective remembering. Brain and Cognition, 44, 103-107.

Park, D.C., Hartzog, C., Kidder, D.P., Morrell, R.W. and Mayhorn, C.B., 1997, Effect of age on eventbased and time-based prospective memory. Psychology and Aging, 12, 314-327.

Rabitt, P., 1978, Detection of errors by skilled typists. Ergonomics, 21, 945-958.

Rasmussen, J., 1987, Mental Models and the Control of Actions in Complex Environments (Report no. 2656), (Roskilde, Denmark: Riso National Laboratory).

ReAson, J., 1984, Lapses of attention in everyday life. In Varieties of Attention, R. Parasuraman and D.R. Davies (Eds.), pp. 515-549 (London: Academic Press).

Reason, J., 1990, Human Error. (Cambridge: Cambridge University Press).

Rizzo, A., Bagnara, S. and Visciola, M., 1987, Human error detection processes. International Journal of ManMachine Studies, 27, 555-570.

Rizzo, A., Ferrante, D. and Bagnara, S., 1995, Handling human error. In Expertise and Technology, J.M. Hoc, P.C. Cacciabue and E. Hollnagel (Eds.), pp. 195-212 (Hillsade, NJ: Erlbaum).

Scheffers, M.K. and Coles, M.G.H., 2000, Performance monitoring in a confusing world: Error-related brain activity, judgements of response accuracy and types of errors. Journal of Experimental Psychology: Human Perception and Performance, 26, 141-151.

Scheffers, M.K., Coles, M.G.H., Bernstein, P., Gehring, W.J. and Donchin, E., 1996, Event-related potentials and error-related processing: An analysis of incorrect responses to go and no-go stimuli. Psychophysiology, 33, $42-53$.

Searle, J.R., 1983, Intentionality: An Essay in the Philosophy of Mind. (Cambridge: Cambridge University Press).

SEllen, A.J., 1990, Mechanisms of human error and human error detection, PhD thesis, University of California, San Diego (published, 1991, University Microfilms, Abstract in Dissertation Abstracts International, 51, 5618).

Sellen, A.J., 1994, Detection of everyday errors. Applied Psychology: An International Review, 43, 475 - 498.

Sellen, A.J., Kurtenbach, G.P. and Buxton, W.A.S., 1990, The role of visual and kinesthetic feedback in the prevention of mode errors. In Human Computer Interaction, INTERACT'90, D. Diaper, P. Gilmore, G. Cockton and B. Shackel (Eds.), pp. 667-673 (Amsterdam: North-Holland).

Sellen, A.J., Louie, G., Harris, J.E. and Wilkins, A.J., 1996, What brings intentions to mind? An in situ study of prospective memory. Memory, 5, 483-507.

Sellen, A.J. and Norman, D.A., 1992, The psychology of slips. In Experimental Slips: Exploring the Architecture of Volition, B.J. Baars (Ed), pp. 317-339 (New York: Plenum Press).

Shallice, T. and Burgess, P., 1991, Higher-order cognitive impairments and frontal lobe lesions in man. In Frontal Lobe Function and Dysfunction, H.S. Levin, H.M. Eisenberg and A.L. Benton (Eds.), pp. 125-138 (New York: Oxford University Press)

Shapiro, J.K., Shapiro, L.R., Russell, S. and Alper, J.S., 1998, A role for executive processes in prospective remembering. Brain and Cognition, 37, 175-177.

Smid, H.G.O.M., Mulder, G. and Mulder, L.J.M., 1990, Selective response activation can begin before recognition is complete: A psychophysiological and error analysis of continuous flow. Acta Psychologica, 74, $169-201$.

Vidal, F., Hasbroucq, T., Grapperon, J. and Bonnet, M., 2000, Is the 'error negativity' specific to errors? Biological Psychology, 51, $109-128$.

Vortac, O.U., Edwards, M.B. and Manning, C.A., 1995, Functions of external cues in prospective memory. Memory, 3, 202-219.

Wehner, T. and Stadler, M., 1994, The cognitive organization of human errors: A gestalt theory perspective. Applied Psychology: An International Review, 43, 565-584.

Wilkins, A.J. and Baddeley, A.D., 1978, Remembering to recall in everyday life: An approach to absentmindedness. In Practical Aspects of Memory, M.M. Gruneberg and P.E. Morris (Eds.), pp. 27 -34 (London: Academic Press).

Woods, D., 1984, Some results on operator performance in emergency events. In Ergonomics Problems in Process Control, Symposium, series no. 90, D. Whitfield (ed.), (London: Institute of Chemical Engineers), pp. 13-21.

ZAPF, D. and REAson, J.T., 1994, Introduction: Human errors and error handling. Applied Psychology: An International Review, 43, 427-432.

Zapf, D., Brodbeck, F.C., Frese, M., Peters, H. and Prümper, J., 1992, Errors in working with computers: A first validation of a taxonomy for observed errors in a field setting. International Journal of Human-Computer Interaction, 4, 311-339. 
Zapf, D., Maier, G.W., Rappensperger, G. and Irmer, C., 1994, Error detection, task characteristics and some consequences for software design. Applied Psychology: An International Review, 43, 499-520.

Zeigarnik, B., 1927, Das Behalten erledigter und unerledigter Handlungen. Psychologische Forschungen, 9, 1 85 . 